\title{
(c) (1) \\ Sombra comunista ou novas realidades? Análise sobre o desenvolvimento da Arquivologia russa na era pós-soviética (1991-2016)
}

\author{
Roberto Lopes dos Santos Junior ${ }^{I}$ \\ http://orcid.org/0000-0001-6063-920X \\ I Universidade Federal do Pará, Belém, PA, Brasil. \\ Doutor em Ciência da informação pelo convênio IBICT/ UFRJ. \\ Professor adjunto da Faculdade de Arquivologia e do Programa \\ de Pós-graduação em Ciência da Informação.
}

http://dx.doi.org/10.1590/1981-5344/3315

Análise histórica - a partir de levantamento bibliográfico e revisão de literatura em fontes secundárias-identificando as principais características que marcaram a Arquivologia na Rússia nas décadas de transição do país para o capitalismo. O período analisado foi entre 1991, com a dissolução da URSS, até 2016, durante o governo de Vladimir Putin. O trabalho divide-se em três partes: discussão sobre a infraestrutura dos acervos e dos cursos de formação de arquivistas russos no período póssoviético, a legislação promulgada durante os anos 1990 e 2000, reorganizando e readaptando os arquivos do país, e a complexa situação da acessibilidade desses conjuntos documentais, principalmente relacionado a pesquisadores e usuários ocidentais. A pesquisa identificou que, apesar de alguns problemas e vícios oriundos do período comunista ainda serem percebidos, tantos os acervos quanto a formação profissional e estrutura legal da área no país abrem-se para um novo horizonte, se adaptando, parcialmente, a realidade capitalista vigente.

Palavras-chave: Arquivologia russa, legislação arquivística, Acesso, Pós-Comunismo 


\title{
Communist shadow or new realities? Analysis about the development of Russian Archival Science in post-soviet era (1991-2016)
}

\begin{abstract}
Historical analysis - based on literature and bibliographic review - identifying the main characteristics about the Russian Archival Science in the decades of the country's transition to capitalism. The period of analysis is between the second half of 1991, with the dissolution of the USSR, to 2016, on the Vladimir Putin's Government. The article is divided in three parts: analysis about the infrastructure of the archives in post-soviet Russia and the professional formation of Russian archivists, discussion about the laws and regulations produced in the 1990s and 2000s, and the complex situation of the accessibility in Russian archives, especially for occidental researchers and users. This research identifies that, despite some problems inherited from the communist era, the archives in Russia, including the professional formation and legal structure, was open to a new horizon, adapting, partially, to the capitalist reality.
\end{abstract}

Keyword: Russian Archival Science, Archives Legislation, Access, Post-communism

Recebido em 18.10.2017 Aceito em 25.04.2019

\section{Introdução}

A Rússia, durante as primeiras décadas do século 21, apresenta uma dinâmica, mesmo que instável, situação política, social e econômica, ainda sofrendo com a difícil transição da realidade oriunda da antiga União Soviética.

Por um lado, o país conseguiu considerável recuperação econômica, revertendo parcialmente as perdas advindas de um quase colapso durante os anos 1990, onde o forte sistema educacional, científico, esportivo e militar herdado do comunismo, mesmo com reveses, pôde ser preservado. No campo artístico, uma geração de cineastas e músicos permitiram a renovação do que seria chamado de "Mundo Russo" (Russki Mir). No 
escopo internacional, o país também recuperou parte do prestígio perdido com a dissolução da URSS, impondo restrições a presença estadunidense na antiga esfera de influência soviética (visível em intervenções do exército russo na Geórgia em 2008, e na Ucrânia em 2014), e na escolha do país para sediar importantes eventos como, por exemplo, a olimpíada de inverno, realizado em Sochi (2014), e na copa do mundo de futebol, realizada em julho de 2018 (SERVICE, 2015).

Por outro, o país apresenta resquícios de um sistema político autoritário, repressivo e centralizador, visíveis nos mandatos do presidente Vladimir Putin (2000-2008 e a partir de 2012), além dos problemas sociais (baixa natalidade, alta taxa de criminalidade e corrupção, elevados índices de alcoolismo e pobreza, hostilidade a minorias e opositores políticos, fuga de cérebros), onde apenas em 2013 começaram, timidamente, a ser abertamente discutidos e, de forma gradual, revertidos (SERVICE, 2015).

Os arquivos russos - a partir de 1992, um dos acervos mais procurados e, quando possível, explorados por pesquisadores ocidentais em diferentes campos científicos - também foram influenciados por esse período de instabilidades e situações paradoxais. Apesar de reorganizada, com a criação de novas legislações e organismos durante a primeira metade dos anos 1990, seja no acesso desses conjuntos documentais, variando entre a abertura ou fechamento, seja no trato dos profissionais e órgãos existentes, passando entre a autonomia a posturas repressivas, a Arquivologia russa, nos últimos vinte e cinco anos, transita entre uma realidade "globalizada" com resquícios da excessiva centralização advinda da era soviética (KRAGH, HEDLUND, 2015).

Qual o estado da arte dos arquivos da Rússia no pós-comunismo? Essa pesquisa- expandindo e atualizando trabalhos que abordaram a evolução da Arquivologia na União Soviética/ Rússia (SANTOS JUNIOR 2012, 2013a, 2013b, 2014) -, analisou o desenvolvimento dos acervos documentais russos, no período entre os anos 1990 até as primeiras décadas do século 21, apresentando a situação contemporânea da arquivística no país.

O trabalho teve como base levantamento bibliográfico e revisão de literatura em periódicos de língua inglesa, russa e portuguesa. Apesar de relativamente escasso, existe material disponível discutindo tanto a situação atual dos acervos russos como das possíveis incoerências e entraves em que os mesmos são disponibilizados aos pesquisadores ocidentais.

A pesquisa está dividida em três partes; inicialmente discute-se a situação organizacional tantos dos arquivos (infraestrutura, instituições e associações) quanto da formação profissional dos arquivistas no país; análise sobre a legislação promulgada aos conjuntos documentais russos, adaptando os acervos a uma nova realidade pós-comunista; e discussão sobre a complexa situação do acesso dos arquivos russos a pesquisadores ocidentais, passando entre iniciativas de abertura com políticas mais restritivas. 


\section{Estrutura organizacional}

Em 1991, na então República Socialista Federativa Soviética da Rússia, seus acervos arquivísticos centralizavam-se no Arquivo Central Estatal (TSGA RSFSR), subdividido em arquivos institucionais ligados a organismos militares e econômicos ${ }^{1}$. Esses órgãos e seus respectivos acervos eram coordenados pelo Fundo Unificado dos Arquivos do Estado (Glavarkhiv), principal organismo ligado a Arquivologia na URSS. Em 12 de outubro de 1991, as funções e acervos ligados ao Glavarkhiv foram transferidos para o Comitê em Assuntos de Arquivo da Federação Russa (Roskomarkhiv) - em setembro de 1992 renomeado como Serviço Estatal para os Arquivos da Rússia (Rosarkhiv) - consolidando-se como o principal órgão a administrar e delimitar os acervos arquivísticos russos (HORHORDINA, VOLKOVA, 2012).

Entre 1992-93 dois organismos seriam reorganizados e teriam sua estrutura delineada a realidade da recém instalada Federação Russa: o Arquivo Estatal da Federação Russa (GARF), e o Instituto de História e Arquivos da Faculdade Estatal Russa para as Humanidades (IAI-RGGU), esse último sendo, por décadas, o principal órgão de formação de arquivistas na URSS. Os diretores desses órgãos, respectivamente Sergei Mironenko e Yuri Afanasiev (1934-2015) - ambos atuantes historiadores durante o governo de Mikhail Gorbachev- , passariam os quinze anos seguintes ocupados com a complexa tarefa de dinamizar essas instituições, permitindo a ascensão de uma nova geração de profissionais e pesquisadores, em conciliar tensões e rusgas entre historiadores e arquivistas, e de manter relações amistosas com o governo russo, o que nem sempre era possível (HORHORDINA,VOLKOVA, 2012).

Também foram vislumbrados o surgimento e consolidação de associações e sociedades ligados a profissionais de arquivo russos, praticamente inexistentes durante o período soviético, com destaque para a Sociedade Russa de Historiadores e Arquivistas (ROIA).

Fundada em dezembro de 1990, nos momentos finais da URSS, a Sociedade, sob a liderança inicial de Yaroslav Schapov (1928-2012), não somente serviu de voz para os arquivistas recém-saídos do comunismo, no qual puderam realizar cursos e congressos discutindo aspectos teóricos e práticos sobre a Arquivologia, mas oferecendo também um local para a troca de informações com bibliotecários, museólogos, jornalistas, além de associações e instituições arquivísticas públicas e privadas ${ }^{2}$. Os congressos nacionais promovidos quinquenalmente pelo órgão são

\footnotetext{
${ }^{1}$ Respectivamente Arquivo Central Estatal da Revolução de Outubro (TSGAOR SSSR); Arquivo Central Estatal da Economia Nacional (TSGANKhSSSR); Arquivo Central Estatal de Arte e Literatura (TSGALI SSSR;) e o Arquivo Central Estatal do Exército Soviético (TSGASA SSSR).

2 Algumas informações sobre o funcionamento, atividades e funções do organismo podem ser obtidas no site http://www.roiarch.com/
} 
considerados os principais eventos de arquivo ocorridos na Rússia, e o periódico científico publicado pelo instituto, Вестник архивиста/ Herald of an Archivist (em atividade desde 1991), é o principal relacionado a área no país ${ }^{3}$. Atualmente o ROIA tem 73 entidades de pesquisa, 15 conselhos ligados aos arquivos das repúblicas e 19 associações profissionais espalhadas pela Rússia (MELNICHUK, 2015; MARAKOVA, 2015).

Contudo, alguns problemas também foram enfrentados pelo organismo ao longo dos anos. Os principais foram relacionados aos limites de atuação entre arquivistas e historiadores em seus respectivos campos de trabalho, debate que se encontra em aberto, e da tênue relação entre a direção do ROIA e o governo russo. As gestões de Alexander Chubaryan (1996-2006), Vladimir Myasnikov (2006-2010) e, principalmente, Efim Pifovar e Ivan Anfertiev (a partir de 2011) não raro se chocaram com os ditames dos presidentes russos sobre 0 funcionamento e trocas informacionais entre os acervos do país (MELNICHUK, 2015; MARAKOVA, 2015).

Entre 2010 e 2013, com a liderança ou supervisão do Arquivo Estatal da Federação Russa, a reorganização dos acervos se estabilizou em 10 instituições principais ${ }^{4}$, além de quatro arquivos em âmbito regional (Moscou, São Petersburgo, Saratov e Tver) responsáveis na difusão e divulgação da Arquivologia russa entre diferentes regiões do país (WILLIMOTT, SHERRY, WATERLOW, 2013).

Durante a década de 1990 e 2000, os arquivos relacionados às regiões russas (definidas no país como Krai e Oblast) ganharam maior autonomia, sendo promulgados leis e regulamentos próprios para cada arquivo federal (16 em atividade em 2017) e regional, onde todas as 22 repúblicas constituintes da Rússia, e seus respectivos Krai (nove) e Oblasts (46) possuíam pelo menos um arquivo em atividade em 2017 (ARCHEOBIBLIOBASE, 2017).

A infraestrutura desses organismos, contudo, patinou por toda a década de 1990. Cortes abruptos de recursos e investimentos, diminuição de salário dos arquivistas, com casos extremos de deterioração de acervos localizados, visualizados na falta de equipamentos, vandalismo, furto, sinistros (incêndios, inundações, etc.) marcaram a Arquivística russa nos primeiros anos pós-URSS. Somente em 2000 a situação se inverteu, com o governo russo investindo maciçamente na reconstrução de vários acervos no país e na renovação dos serviços, muitos deles presos a práticas realizadas na era comunista. O processo ainda está em andamento, contudo com melhorias tanto na constituição dos acervos como no atendimento oferecido ao público usuário desses conjuntos documentais (KELLAR, 2012a).

\footnotetext{
${ }^{3}$ Em seus primeiros anos denominado "Revista da Sociedade Russa de Historiadores e Arquivistas", disponível nos sites http://www.arhivemagazine.com/ (resumos em inglês dos artigos) e http://www.vestarchive.ru/ (com os artigos completos em cirílico)

${ }^{4}$ Respectivamente Arquivo de Política Estrangeira da Federação Russa; Arquivo de Filmes da Federação Russa (GOSFIL'MOFOND); Arquivo Estatal de Arte Antiga Russa; Arquivo Estatal de Literatura Russa; Arquivo Estatal da Política Histórica e Social Russa; Arquivo Estatal da História Russa Contemporânea; Arquivo Estatal do Ministério Militar Russo; Arquivo Estatal Histórico Russo; e seções ligadas a Biblioteca Estatal Russa (LENINKA) e do Museu Histórico e Estatal Russo (WILLIMOTT, SHERRY, WATERLOW, 2013).
} 
A informatização dos arquivos russos, problema existente desde os anos 1980, apresentou duas fases: a primeira, entre 1992-94, onde apesar dos projetos de automação isolados (grande parte deles realizados em Moscou), a entrada de computadores nos centros documentais do país mostrou-se lenta. Contudo, com a consolidação do ArcheoBiblioBase (http://www.iisg.nl/abb/), base de dados reunindo informações sobre os arquivos da Rússia, implantada entre 1994 e 1996, e do Russian Archives Online (http://www.russianarchives.com/), principal repositório de documentos textuais e audiovisuais dos acervos russos, consolidado em 1998, os arquivos da Rússia, depois de quase duas décadas de tentativas, finalmente entravam em uma realidade computadorizada (KELLAR, 2012a).

A segunda fase seria visualizada a partir dos anos 2000, com programas estatais de renovação tecnológica promovidas pelo governo russo, onde os arquivos centrais e regionais também teriam a disposição um novo leque de hardwares e softwares. Mesmo que, entre 2015-2016, ainda se percebesse discrepâncias sobre o grau de assimilação automatizada entre diferentes acervos regionais (forte em centros como Moscou, São Petersburgo e Novosibirsk, irregular ou mais fragilizadas no extremo oriente russo), os arquivos do país encontravam-se em situação mais positiva do que em anos anteriores (KELLAR, 2012a; SKUFINA, BARANOV, SAMARINA, 2016). Cita-se também que tanto no IAI-RGGU como em diferentes centros de ensino em Arquivologia, os profissionais têm acesso a uma cadeira dedicada a gestão de documentos eletrônicos e digitais (KELLAR, 2012a).

Em relação a formação de profissionais ligados a Arquivologia, Guseva e Marakova (2015) afirmam que, nos últimos anos, consolidou-se quatro principais locais de estudo: centros educacionais e colégios/cursos técnicos (segundo as autoras, dezenas em atividade por toda a Rússia); curso de bacharelado, boa parte deles com foco em gestão de documentos; mestrados, na Rússia separado em dois tipos, um ligado aos arquivos históricos/ permanentes e outro ligado a gestão eletrônica de documentos; e centros de aprimoramento e atualização de arquivistas ligados a acervos públicos/privados e no tratamento informacional em departamentos governamentais. Em meados dos anos 2000, criou-se o primeiro Departamento em Documentação e Arquivologia, na Universidade Estatal de Magnitogorsk, delineando currículos desses centros de estudo, tendo seu primeiro pós-graduando formado em 2011.

Segundo Larin (2014), cita-se como caminho importante de formação e especialização de arquivistas a constituição de novas cadeiras de ensino para profissionais em arquivo no já citado Instituto de História e Arquivos da Faculdade Estatal Russa para as Humanidades (IAI-RGGU). Separado em cinco módulos principais (disciplinas humanitárias, sociais e econômicas, disciplinas matemáticas e naturais, disciplinas de especialização geral, disciplinas especializadas, e disciplinas optativas), o curso se relacionou a duas reformas curriculares promovidas pelo governo russo, respectivamente em 2003 e entre 2009-2011, criando dois 
programas de ensino ligados aos arquivos: 03.20.02- Suporte documental para a Administração e Arquivologia (graduação) e 05.25.02Documentação, gestão de documentos e Arquivologia (pós-graduação).

\section{Legislação}

No final de 1991 e início do ano seguinte, novas leis e regulamentos começaram a ser discutidos entre o governo e diferentes instituições arquivísticas russas, adaptando a Arquivologia e seus acervos ao póscomunismo ${ }^{5}$. Em junho de 1992 foi promulgado o "Regulamento sobre o acesso temporário de materiais de arquivo e de sua utilização", o "Regulamento sobre a conservação da documentação dos arquivos da Federação Russa em âmbito federal e regional", e em 22 de dezembro o "Regulamento sobre o Serviço Estatal dos Arquivos da Rússia" (BARREAU, 2012).

Em julho de 1993, foi promulgada a "Lei sobre os fundos de arquivo da Federação Russa e seus acervos", considerada a principal a regulamentar e identificar as funções, estrutura, organização e funcionamento dos arquivos russos no pós-comunismo. Em dezembro de 1993, com a promulgação da primeira constituição da Federação Russa, a lei de arquivos recebeu breves modificações para sua adaptação com a "Lei de informações da Federação Russa", ressaltando a importância do cidadão russo em obter informações pessoais nos acervos do país, mas também estipulando barreiras a utilização e consulta desses arquivos. Após longas (e tensas) discussões, a versão final da lei dos arquivos foi promulgada em 2004, mantendo as barreiras estipuladas na década anterior (BARREAU, 2012).

Em 1994, com o "Regulamento sobre os fundos de arquivo da Federação Russa" emendas foram adicionadas garantindo o sigilo e impenetrabilidade dos arquivos relacionados ao politburo ${ }^{6}$, a presidência, e em acervos dos órgãos de segurança e defesa russos. Emendas realizadas entre 1999 e 2009 manteriam a "não acessibilidade" desses acervos, contudo identificando o grau de sigilo (ou seja, a duração dessa confidencialidade) no qual esses acervos se encontram (BARREAU, 2012).

Duas iniciativas, contudo, destoaram da tendência de fechamento dos acervos no país. Em 1996 foi criado a "Comissão de manutenção do sigilo documental" onde, apesar do título, produziu regimentos que permitiram a desclassificação de dezenas de milhares de documentos dos arquivos estatais russos, postura essa mantida nos vinte anos seguintes. Outro comitê, também de nome peculiar, de "Contra tentativas de falsificação histórica contrários aos interesses da Rússia", em atividade entre 2009-2012, discutiu não somente sobre a confidencialidade, mas também sobre as práticas de falsificação documental existentes nos

\footnotetext{
${ }^{5}$ Durante a existência da União Soviética, a principal lei que serviu de base para as emendas e regulamentos aos acervos arquivísticos do país foi a "Declaração de direitos sobre a Ciência dos Arquivos", assinado em primeiro de junho de 1918, definindo o funcionamento e hierarquização dos acervos da URSS (GRIMSTEAD, 1982; KELLAR, 2012b).

${ }^{6}$ Politicheske Byuro (Gabinete de Política), foi o órgão executivo do Partido Comunista na URSS, substituído em 1994 pelo parlamento russo (Duma).
} 
arquivos soviéticos, e de forte ocorrência durante o governo de Josef Stalin (1928-1953). Algumas normas e projetos de lei foram discutidos sobre o tema, contudo uma legislação especifica sobre a fiabilidade dos conjuntos documentais adulterados e/ou modificados nos acervos russos acabaram não sendo desenvolvidos (HOBSON, 2016; KRAMER, 2012).

A partir da segunda metade da década de 1990, leis e regulamentos promulgados focaram na disponibilidade e possibilidades de restituição desses acervos para outros países. Entre 1998 e 2000 foram promulgadas leis referentes a propriedade cultural do país, com normas relacionadas a recuperação ou devolução de documentos de arquivo ou obras de arte para países em que a Rússia combateu ou apoiou durante a Segunda Guerra Mundial. Começava uma longa negociação, via meios legais, principalmente com a Alemanha, em obter possíveis reparações de material saqueado pelas tropas soviéticas ou nazistas durante o conflito (GRIMSTEAD, 2011).

\section{Da "revolução dos arquivos" a um (parcial) fechamento: analise do acesso aos acervos russos.}

As origens e autoria do conceito "revolução dos arquivos", relacionado a abertura dos acervos na Rússia para pesquisadores ocidentais, permitindo novos horizontes de pesquisa para a história soviética, são obscuras. O termo, na verdade, apesar de consideravelmente citado, só obteve análises retrospectivas mais aprofundadas no início do século 21, quando a "revolução" se esvaiu com a promulgação de medidas mais restritivas de consulta (e.g. PAMPLER, 2003; RALEIGH, 2002).

A questão, contudo, precisa de uma abordagem cautelosa pois, apesar do acesso mais amplo e menos restritivo comparado ao que existia durante o período soviético, todos os três presidentes da Federação Russa (Boris Yeltsin, Dmitri Medvedev e Vladimir Putin) alternaram, em seus mandatos, posturas conciliatórias com políticas de fechamento dos acervos no país.

Essas incoerências seriam percebidas durante o (tumultuado) governo de Boris Yeltsin (1992-1999), onde se, por um lado, extensos fundos arquivísticos ligados ao partido comunista seriam abertos a pesquisadores e público, o acervo presidencial, do Serviço Federal de Segurança da Federação Russa7, do Ministério do Exército e de Relações Exteriores continuaram fechados, tendência essa mantida nos governos seguintes. Entre 1993-95, os arquivos do Partido Comunista Soviético foram fechados para reformas. Ao serem reabertos, a partir de leis ligados aos arquivos promulgados nesse período, parte considerável desses acervos tiveram restrições de acesso, frustrando alguns pesquisadores ocidentais (BLUM,2013; KRAMER, 2012).

\footnotetext{
7 Em russo Федеральная служба безопасности Российской Федерации, instituída em 1995, substituiu o Comitê de Segurança do Estado (KGB), dissolvido em dezembro de 1991.
} 
O governo Putin manteria, e intensificaria, essas restrições. Em 2003, cerca de 135 fundos de arquivo ligados ao Partido Comunista Soviético foram fechados, com milhares de documentos ficando indisponíveis para consulta tanto para pesquisadores russos quanto estrangeiros. Contudo, essa postura mostrou-se mais como continuidade de iniciativas feitas pelo governo anterior do que uma nova era de fechamento. A partir de 2008, esses fundos seriam, de forma gradativa, reabertos aos pesquisadores (KRAMER, 2012).

Por outro lado, o país, buscando melhores relações com o ocidente e os EUA, retiraram alguns entraves que barravam 0 intercâmbio documental ou de arquivistas entre esses países. Entre diferentes iniciativas que indicavam essa nova postura citam-se trocas de documentos com a França, Holanda e Coréia do Sul, e projetos de conservação, armazenamento e microfilmagem de acervos russos em conjunto com o Institut fürZeitgeschichte (Alemanha), Library of Congress (EUA), American Historical Association, American Association for the Advancement of Slavic Studies e com o Cold War International History Project, ligado ao Woodrow Wilson International Center for Scholars, em Washington (BAYERLEIN,2016).

Outro aspecto a ser considerado foram acordos assinados pelos governos Putin e Medvedev de cooperação a países europeus e antigas repúblicas soviéticas. Cita-se, por exemplo, o "Acordo de proteção mútua de informação sigilosa" assinado em junho de 2004, relacionada a Organização do Tratado Coletivo de Segurança (aliança militar criada em 1992 incorporando algumas ex-repúblicas soviéticas). Apesar do nome, o regimento permitiu aos países pertencentes do organismo (na época Rússia, Armênia, Bielorrússia, Cazaquistão, Quirguistão e Tadjiquistão) trocassem documentos e informações entre seus arquivos nacionais, além de visitas de arquivistas nesses acervos. Essa inciativa seria expandida com o "Acordo de procedimentos de revisão dos critérios de informação confidencial e sigilosa existentes durante a União Soviética", assinado em outubro de 2011, onde Rússia, Armênia, Bielorrússia e Uzbequistão concordaram não somente na revisão do grau de sigilo de conjuntos documentais ligados ao partido comunista, mas que o processo fosse realizado em conjunto, nos casos onde os documentos possuíam mais de uma antiga república soviética de origem (KRAMER, 2012).

Durante esses governos ocorreu também um dos maiores projetos de cooperação entre acervos arquivísticos em âmbito internacional, entre a Universidade de Colorado (EUA), a Universidade Estatal de Saratov e o Centro Internacional de Estudos Russo-Germânicos (ICGRS), reunindo bibliotecários e arquivistas estadunidenses e russos, com o suporte de historiadores, advogados, administradores e membros de comunidades locais, que realizaram visitas em acervos arquivísticos na região de Saratov, com um plano de reorganização, atualização e reclassificação desses acervos no período entre 2006-2010. Essas ações culminaram com a conferência de estudos russo-germânicos, realizado em outubro de 2010, permitindo que pesquisadores dos EUA e Rússia pudessem realizar 
visitas frequentes aos arquivos dos dois países, e na consolidação de um projeto de atualização dos arquivos estatais e regionais de Saratov (BISHOP, ROCK, 2010).

Indica-se também a boa vontade (parcial) da Rússia em trocas documentais e restituições com países do leste europeu. Nos anos 1990, mas principalmente entre 2000-2009, foram efetuados acordos com a Alemanha, República Tcheca, Eslováquia, Hungria e Romênia. Durante o século 21, cita-se o interesse do governo russo, mesmo com reservas, na abertura ampla de documentos sobre o massacre de 22 mil poloneses por tropas soviéticas em Katyn (1940), num processo de melhoria das relações entre a Rússia e a Polônia, e da tentativa de novas interações do país com a região. Infelizmente, a morte do presidente polonês Lech Kaczynski, e de dezenas de membros do governo e da Assembleia Nacional da Polônia no acidente aéreo em Smolensk, em abril de 2010, esfriou essas iniciativas, mas que seriam continuadas nos anos seguintes (KRAMER, 2012).

A saída de Sergei Mironenko da direção do Arquivo Estatal da Federação Russa, em março de 2016, aparentemente relacionado a desmentidos da instituição, provados documentalmente, sobre a existência da "Guarda Panfilov" (28 soldados soviéticos que destruíram diversos tanques alemães e ajudaram a impedir a queda de Moscou em 1941) indicavam mais um novo capítulo de fechamento dos acervos ou instituições russas. Porém, a nova diretora, Larisa Rogoyava, manteve as políticas e iniciativas de seu antecessor, criando tensões com o Ministro da Cultura Vladimir Medinsky, que, em mais de uma ocasião, criticou as medidas feitas pelos arquivos da Rússia de abrirem parte de seus acervos (HOBSON, 2016; SPARKS,2016).

Fitzpratck (2015), experiente historiadora ligada a arquivos russos, apresentou conciso resumo sobre o "estado da arte" dessa abertura, focando em sua experiencia aos acervos da URSS e Rússia, o qual visitou desde os anos 1970. Primeiramente, a autora, discordando de influente corrente de historiadores, se opõe a teoria da "impenetrabilidade" ou "inacessibilidade" dos acervos soviéticos. Segundo a historiadora, apesar da existência de diversos entraves burocráticos e dificuldades de acesso, existiram pesquisadores ocidentais que puderam realizar pesquisas a partir de fontes primárias disponibilizadas pelos acervos arquivísticos da URSS, em especial durante os anos $1970^{8}$. Contudo, Fitzpatrick concorda que somente no governo de Gorbachev que o acesso documental e trocas informacionais entre organismos soviéticos e norte-americanos se intensificaram, sendo fortalecidos durante o governo de Yeltsin. A "revolução dos arquivos", segundo a autora termo cunhado pelos próprios russos para superestimar a abertura de seus acervos, sempre foi um fenômeno limitado, mas nunca totalmente encerrado, mesmo com o parcial fechamento promovido após 2000. Centenas de teses e livros,

\footnotetext{
${ }^{8}$ Entretanto a autora admite que a possibilidade de produção de material científico a partir desses acervos foi tardia, identificando o trabalho mais antigo feito por um inglês, usando dessas fontes primárias, apenas em 1968 (Prelude to Revolution: The Petrograd Bolsheviks and the July 1917 Uprising, de Alexander Rabinowitch).
} 
publicados por autores europeus e estadunidenses, a partir de fontes primárias, comprovam que o acesso dos arquivos russos, apesar dos problemas, é mais positivo que nos tempos soviéticos, e que o retorno ao período comunista de fechamento mostra-se consideravelmente improvável.

Um último aspecto ligado ao acesso dos documentos russos relaciona-se a acervos independentes, não governamentais, muitos deles críticos a versão oficial da história soviética (ou, mais raramente, laudatórios a esse passado), originados nos últimos anos do regime comunista9. Apesar de prolíficos na recuperação e disponibilização de documentos, a maioria, seja pela repressão do governo russo, pela baixa procura a seus acervos, ou ambos os fatores, caíram no ostracismo ou seriam fechados durante o final dos anos 1990 e meados da década seguinte (FOREST, JOHNSON, 2002; MARTIN, 2016). Porém existiram importantes exceções.

A principal é a Sociedade Memorial. Fundado em 1987 por proeminentes personalidades como, por exemplo, o físico e Prêmio Nobel da Paz Andrei Sakharov (1921-1989), o organismo, em mais de 25 anos de existência, se transformou em um dos maiores acervos independentes relacionados ao regime stalinista. Seus arquivos, relacionados a "História política das repressões ocorridas na União Soviética", "História dos dissidentes soviéticos", e conjuntos documentais ligados a história oral e biográfica, são considerados referência por diferentes instituições europeias. Atualmente, seu centro de documentação (museu, biblioteca e arquivo) contém mais de 13 mil documentos, além de um banco de dados disponível ao público em diferentes locais da Rússia ${ }^{10}$.

O organismo, durante sua existência, recebeu tratamento diferenciado no exterior e na Rússia. No âmbito internacional, as inciativas do organismo receberam elogios e diversos prêmios na Europa e Estados Unidos, chegando a concorrer ao Prêmio Nobel da Paz em 2014. Na Rússia, a relação do Memorial com o governo mostra-se tensa, por vezes com posturas agressivas advindas da administração Putin-Medvedev. Entre esses antagonismos cita-se assassinatos de membros do organismo (como, por exemplo, de Natalya Estemirova, em 2009 na Chechênia), casos de vandalismo, em especial a retirada de 12 computadores e banco de dados da instituição, a mando presidencial, em 2008 (sendo devolvidos por mandado judicial em meados do ano seguinte), e de comentários hostis de membros do governo, exemplificados em afirmações do Ministro da Justiça Alexander Konovalov, em 2014, de que o Memorial, pelo bem da Rússia, deveria ser "liquidado" o mais rápido possível (MARTIN, 2016).

\footnotetext{
${ }^{9}$ As origens dessas iniciativas surgem em práticas coordenadas pelos "dissidentes" (intelectuais ou membros do partido comunista que se opuseram de forma aberta ao regime), na tentativa de se reavaliar certos aspectos da história soviética, baseando-se principalmente em depoimentos de sobreviventes ou personagens que participaram desses acontecimentos. A partir desse material, toda uma produção underground chamada de Samizdat (livros não autorizados) e Magnitizdat (material produzido e distribuído em fitas k7) floresceu entre a segunda metade dos anos 1970 e a primeira metade dos 1980 (SANTOS JUNIOR, 2012; MARTIN, 2014).

10 Informações obtidas no flyer disponibilizado pela The Memorial Society Archive, na página http://old.memo.ru/library/arh eng.pdf Acesso em 10 de outubro de 2017.
} 


\section{Considerações finais}

O presente artigo analisou as principais características que delinearam os arquivos e a Arquivolgia russa nas primeiras décadas póscomunistas.

Em um primeiro momento devemos identificar como a Rússia se constituiu a partir de 1991. Se por um lado foi percebido que a saída de cena da URSS surpreendeu e consternou muitos, onde, segundo Service (2015, p.611), "o partido comunista, sua ideologia, bandeira, hino, e a revolução de outubro desapareceram [...] de forma extraordinariamente abrupta", por outro não devemos superestimar essas mudanças, pois a transição para a democracia mostrou-se defeituosa e incompleta, com o país governado por experientes autocratas ligados ao período soviético. No século 21, se a Rússia estava incorporada a uma realidade capitalista, e com pouco interesse em sair dela, também foi observado que "os comunistas, ou seus parceiros, permaneceram no poder, apenas sob uma nova nomenclatura e novas pautas 'ocidentais'" onde "funcionários do alto escalão do antigo regime foram, discretamente, reciclados e reinstituídos ao poder" (JUDT, 2008, p.689).

É nesse ambiente onde diferentes propostas, de forma confusa, se mesclavam, que os arquivos russos estão inseridos. Cita-se que existiram mudanças, adaptações e reorganização nos acervos arquivísticos, seja em seu funcionamento, infraestrutura ou serviços, além de novos currículos renovando e ampliando o campo de atuação dos arquivistas a uma realidade globalizada e mais tecnológica. Porém, essa reordenação e renovação mostra-se ainda em desenvolvimento, onde os deletérios efeitos da grave situação econômica do país nos anos 1990 ainda são sentidos.

Os organismos e instituições também tiveram sua estrutura readaptada a uma nova realidade política e social. Compreensivelmente, antigas estruturas ainda servem, de forma parcial, como base para esses órgãos. Porém novas reordenações estruturais permitiram, finalmente, a descentralização dos acervos russos, processo que se mostraria consolidado na década de 2010, encerrando com a principal característica que identificava os arquivos da União Soviética.

É no âmbito da legislação e acesso que os choques entre passado e presente podem ser melhor identificados nos conjuntos documentais da Rússia. Por um lado, foi percebido maior abertura e projetos de cooperação tanto internamente como no exterior, o que as políticas mais fechadas de Vladimir Putin apenas diminuíram. Por outro, sejam por leis mais restritivas ou posturas menos amistosas de alguns setores governamentais, foi identificado que, apesar de existir consciência ao direito do cidadão russo e dos organismos internacionais a informação arquivística, as inciativas são apresentadas com limites, por vezes não estipuladas claramente pelo governo. 
Por fim, foi identificado que, apesar de alguns reveses e problemas ainda à guisa de solução, a Arquivologia russa encontra-se numa realidade onde os antigos laços comunistas, gradativamente, estão sendo desamarrados.

\section{Referências}

ArcheoBiblioBase. Regional Archives of the Russian Federation. 11/09/2017. Disponível em: http://www.iisg.nl/abb/rusfed.php Acesso em 12 de outubro de 2017

BARREAU, I. Le système et la législation archivistiques en Russie 20 ans après la fin de I'Union Soviétique. Dissertação (Mestrado em Biblioteconomia e Ciência da Informação), Universidade de Montreal, 2012.

BAYERLEIN. B. H. Arquivos do comunismo e perspectivas de pesquisa 25 anos após a "Revolução dos Arquivos": um balanço global. Estudos Históricos, vol. 29, no 59, p. 787-812, 2016.

BISHOP, J. ROCK, K. "A Long Way from Moscow": A Collaborative Project between Archivists, Librarians, and Historians from the Steppes of Saratov Province and the High Plains of Colorado. Collaborative Librarianship: v. 2, no 3, p.113-134, 2010.

BLUM, D. A. Managment of Inteligence archives in fallen authoritarian regimes. Dissertação (Mestrado em Estudos da Informação e Bibliotecas). Alabama, Universidade do Alabama, 2013.

FITZPATRICK, S. Impact of the Opening of Soviet Archives on Western Scholarship on Soviet Social History. Russian Review, v.74, n03, 377-400, 2015.

FOREST, B.; JOHNSON, J. Unraveling the threads of history: soviet-era monuments and post-soviet national identity in Moscow. Annals of the Association of American Geographers, v. 92, no 3, p.524-547, 2002.

GRIMSTEAD, P. K. Lenin's archival decree of 1918: the Bolshevik legacy for soviet archival theory and practice, American Archivist, v. 45, n. 4, p. 429-443, 1982.

GRIMSTEAD, P. K. Archival Transition in Russia and the Legacy of Displaced European Archives. Solanus, v.22, p.185-210, 2011.

GUSEVA, L.; MARAKOVA, A. Traditions and moderns trends of the russian and french archival education. Revista Criar Educação, v. 5, nº1, 2015.

HOBSON P. Battle in the Archives - Uncovering Russia's Secret Past. The Moscow times. 24/03/ 2016. Disponível em: https://themoscowtimes.com/articles/battle-in-the-archives-uncoveringrussias-secret-past-52254. Acesso em 10 de outubro de 2017.

HORHORDINA, T. ;VOLKOVA, T. Российские архивы: история и современность. Moscou: RGGU, 2012. 
JUDT, T. Pós-guerra: uma história da Europa desde 1945. Rio de Janeiro: Objetiva, 2008.

KOLAR, K. A. Russian Archives and Libraries: Their Development Since the Introduction of Technology. In: SHARMA, R. N. (org.) Technology and libraries in the twenty first century: An international perspective. Berlim: De Gruyter Saur, 2012a, p: 269-279.

KOLAR, K. A. "What Kind of Past Should the Future Have?": The Development of the Soviet Archival System, 1917-1931. Tese (Doutorado em História). Califórnia: Universidade da Califórnia, 2012b.

KRAGH, M.; HEDLUND, S. Researching Soviet Archives: An Introduction, Russian Review, v. 74, no. 3, p. 373-376, 2015.

KRAMER, M. Archival policies and historical memory in the post-soviet era. Demokratizatsiya: The Journal of Post-Soviet Democratization, v. 20, no 3, p. 204-215, 2012.

LARIN, M. V. Modern Tendencies of Archival Education in Russia. Atlanti, v.24, n02, p.159-164, 2014.

MARAKOVA, A. Развитие университетских систем российского и французского обучения архивистов: история и проблемы современности. Интернет-журнал Науковедение, v.7, no4, p.1-15, 2015.

MARTIN, B. Soviet dissident historians as a societal phenomenon of the post-Stalin era (1956-1985), International Journal of Russian Studies, v.3, no1, p.1-18, 2014.

MARTIN, B. History as Dissent: Independent Historians in the Late Soviet Era and Post-Soviet Russia: From "Pamiat" to Memorial. In: DORFMAN, B. Dissent! Refracted: Histories, Aesthetics and Cultures of Dissent (Political and Social Change). Alemanha: Peter Lang GmbH, 2016, p.53-75.

MELNICHUK, A. Проблема кадрового обеспечения архивных учреждений Российской Федерации. Материалы Ивановских чтений, v.5, p334-238, 2015.

PLAMPER, J. Archival revolution or illusion? Historicizing the Russian Archives and our work in them. Jahrbücher für Geschichte Osteuropas, v. 51, n. 1, p. 57-69, 2003.

RALEIGH, D. Doing soviet history: the impact of the archival revolution. Russian Review, v. 61, n.1, p.16-24, 2002.

SANTOS JUNIOR, R. L.. Análise histórica sobre o desenvolvimento da Arquivologia na antiga União Soviética (1918-1985). InCID: Revista de Ciência da Informação e Documentação, v. 3, p. 64-83, 2012.

SANTOS JUNIOR, R. L. Análise sobre a abertura dos arquivos russos no pós-comunismo a partir da interpretação de pesquisadores norteamericanos e europeus (1993-2013). In: VIII Semana de História Política/ 
V Seminário nacional de história, Rio de Janeiro: UERJ/ PPGH, 2013a, v. 2. p. 1387-1396.

SANTOS JUNIOR, R. L. Depois da Perestróika: Análise histórica sobre a Arquivologia russa nos primeiros anos do pós comunismo (1991-1994). Ágora, v. 23, p. 85-107, 2013 b.

SANTOS JUNIOR, R. L. Arquivos entre a Glasnost e Perestroica: análise histórica sobre a Arquivologia soviética nos últimos anos da URSS (19861991). In: IX Semana de História Política: Política, Conflitos e Identidades na Modernidade. Rio de Janeiro: UERJ / PPGH, 2014, p. 3003-3010.

SERVICE, R. The penguin history of modern Russia: from tsarism to the twenty-first century. 4. ed. Londres: Penguin Books, 2015.

SKUFINA, T.; BARANOV, S.; SAMARINA, V. Dependency between economic development of Russian regions and their level of informatization. Actual Problems in Economics, v.7, no 181, p.485493, 2016.

SPARKS, J. How Russia is engaged in a battle for its own history. Sky News. 11/12/2016. Disponível em: http://news.sky.com/story/howrussia-is-engaged-in-a-battle-for-its-own-history-10691897 Acesso em 10 de outubro de 2017.

WILLIMOTT, J.; SHERRY, S.; WATERLOW, A. Using archives and libraries in the former Soviet Union. Londres: British Association for Slavonic and East European 2013.2 Disponível em: https://www.academia.edu/4204329/Using Archives and Libraries in th e Former Soviet Union v.2.0?auto=download Acesso em 09 de outubro de 2017. 